Research Article

\title{
Research on Investment Environment Performance Evaluation of Blockchain Industry with Intuitionistic Fuzzy CODAS Method
}

\author{
Yong Xu \\ School of Electrical Engineering and Computer, Jilin Jianzhu University, Changchun 130118, Jilin, China \\ Correspondence should be addressed to Yong Xu; xuyong@jlju.edu.cn
}

Received 22 May 2021; Revised 30 July 2021; Accepted 3 November 2021; Published 22 November 2021

Academic Editor: Jianping Gou

Copyright (c) 2021 Yong Xu. This is an open access article distributed under the Creative Commons Attribution License, which permits unrestricted use, distribution, and reproduction in any medium, provided the original work is properly cited.

With global resource waste and environmental pollution becoming increasingly serious, corporate investment environmental performance (CIEP) of blockchain industry has received much attention from researchers over the past decade. As an important part of economic development, enterprises also pay increasing attention to environmental protection and pollution control. CIEP of blockchain industry is regarded as the result of corporate environmental management. Assessing CIEP of blockchain industry can not only make enterprises focus on the environmental protection and management but also promote sustainable social development. Also, it is always viewed as multiattribute group decision making (MAGDM). Thus, a new MAGDM model is used to tackle it. Based on the CODAS (combinative distance-based assessment) method and intuitionistic fuzzy sets (IFSs), this paper designs the distance-based IF-CODAS method to assess CIEP. Eventually, an application about CIEP evaluation is employed to show the superiority of the defined method. The results illustrate that the defined framework is very useful for assessing CIEP.

\section{Introduction}

With the development of new science and technology, the global economy has made great progress than before, but the rapidly economic development has also contributed some impacts to the ecological environment. Numerous countries and regions have encountered the depletion of natural resources and the destruction of the ecological environment which have attracted increasing attention. Nowadays, the conventional economic performance evaluation model cannot satisfy enterprises' evaluation requirements any more. Adding environmental impact factors into the evaluation is necessary, which can not only help enterprises to comprehensively evaluate their performance but also help them to achieve sustainable development. While various enterprises' environmental awareness is weak, they only pay attention to economic development and ignore the management of environmental performance. Therefore, it is indispensable for the enterprises to consider corporate investment environmental performance (CIEP) of blockchain industry in the market competition while creating economic benefits.
Like more and more phenomena in organizational management, CIEP cannot be solved directly. Thus, for enterprises, evaluating CIEP can be regarded as a great challenge. In order to overcome it, the CODAS method for MAGDM under IFSs is designed to tackle this issue. Our work's contributions can be summarized as follows:

(1) Although Karagoz et al. [1] extended the CODAS method to IFSs, these measures shall generate situations which are contrary to intuition and do not consider hesitation in IFSs. On the contrary, depending on novel distance measures, our method can reflect intuitionistic fuzzy information more comprehensively. Besides, the novel distance measures do not generate counterintuitive situations.

(2) There are various criteria in the CIEP evaluation which frequently have different weights. Since the DMs are limited because of their knowledge, it is worthy to give the criteria weights correctly. In this paper, an objective weight determining method is presented. 
The rest of the paper is organized as follows. A literature review is shown in Section 2. Some knowledge of IFSs is listed in Section 3. The CODAS method under IFSs and the calculating steps are defined in Section 4. An empirical example for evaluating CIEP of blockchain industry is given in Section 5. Then, an overall conclusion is given in Section 6.

\section{Literature Review}

2.1. The Evaluation Criteria for CIEP. As environmental awareness is increasing throughout society, for enterprises, if they want to obtain stakeholders' support for operations and development, taking environmental performance indicators into consideration is essential. Therefore, building the scientific evaluation criteria to evaluate CIEP is necessary. Rao et al. [2] pointed out that environmental management and environmental performance were the main assessment criteria of CIEP. Xie and Hayase [3] thought there were two indicators in CIEP. Trumpp et al. [4] determined four criteria for CIEP assessment. Puig et al. [5] identified three categories in the indicators of CIEP as management performance, operational performance, and environmental condition and then specified them, respectively.

\subsection{The Evaluation Method for CIEP. Designing an appro-} priate assessment method for evaluating CIEP is one of the keys to realize a successful sustainable development. There have existed various methods to tackle this issue. For example, Cucchiella et al. [6] developed a method which can directly compare nations called multicriteria decision analysis (MCDA). Elena et al. [7] constructed a framework for CIEP evaluation based on the TOPSIS method. Jiang et al. [8] designed a MCDM technique called AHP to assess CIEP. Jiang et al. [9] put forward a novel method for CIEP assessment on the basis of an impact matrix.

2.3. IFSs. Since the process of evaluating CIEP is full of uncertainty [10-14], in order to show the correctness of DM, Zadeh [15] proposed the fuzzy sets (FSs). Atanassov [16] defined the IFSs. In IFSs, there are two mathematical functions expressing the membership and non-membership [17-21]. Xu and Yager [22] proposed some intuitionistic fuzzy BM (IFBM) operators. Xu and Chen [23] studied these operators under IVIFSs. Hung and Yang [24] analyzed the similarity measures of IFSs. Park et al. [25] defined the distance measures of IVFSs. Hung et al. [26] built the IFTOPSIS method. Beliakov et al. [27] defined the generalized BM operator under IFSs. Ye [28] provided the cross-entropy under IVIFSs (IVIFSs). Xiao et al. [20] defined the intuitionistic fuzzy taxonomy method. Xia et al. [29] built the generalized BM (GIFBM) operators under IFSs. He et al. [30] discussed BM operators based on hesitant fuzzy environment and power operation. Ali et al. [31] defined a graphical method for ranking IFSs. Xiao [32] built distance measure for IFSs for pattern classification problems. Xiao et al. [33] defined the taxonomy method for multiattribute group decision making based on interval-valued intuitionistic fuzzy with entropy. Zhang et al. [34] built the GRA method based on cumulative prospect theory for intuitionistic fuzzy MAGDM. Zhao et al. [35] built the intuitionistic fuzzy MABAC method based on cumulative prospect theory. Xiao [36] defined the evidential fuzzy multicriteria decision making based on belief entropy. Zhao et al. [37]defined the TODIM method for intuitionistic fuzzy MAGDM based on cumulative prospect theory.

The CODAS method was initially developed by Ghorabaee et al. [38] to solve MAGDM. Compared with other MAGDM models, the CODAS method improves the precision of ranking results by integrating Euclidean distance and Hamming distance. Ghorabaee et al. [39] designed the CODAS method by using the trapezoidal fuzzy numbers. Pamucar et al. [40] presented an original pairwise-CODAS method for MCDM. Roy et al. [41] established the CODAS method for MCDM issues with IVIFSs. Lan et al. [42] defined the interval-valued bipolar uncertain linguistic CODAS method. He et al. [43] defined the CODAS procedures for 2-tuple linguistic Pythagorean fuzzy MAGDM. Lei et al. [44] built the probabilistic double hierarchy linguistic CODAS method. Wei et al. [45] defined the probabilistic uncertain linguistic CODAS method.

\section{Preliminaries}

\subsection{IFSs}

Definition 1 (see [16]). An IFS on the space $X$ is given:

$$
I=\left\{\left\langle x, \mu_{I}(x), v_{I}(x)\right\rangle \mid x \in X\right\},
$$

where $\mu_{I}(x) \in[0,1]$ is named the "membership" and $v_{I}(x) \in[0,1]$ is named the "non-membership" and $\mu_{I}(x)$, $\nu_{I}(x)$ satisfy the mathematical condition: $0 \leq \mu_{I}(x)+$ $\nu_{I}(x) \leq 1, \forall x \in X$. For convenience, the intuitionistic fuzzy number is depicted as $I=(\mu, \nu)$, satisfying the condition $\mu \in[0,1], \nu \in[0,1]$, and $0 \leq \mu+\nu \leq 1$.

Definition 2 (see [46]). Let $I_{1}=\left(\mu_{1}, v_{1}\right)$ and $I_{2}=\left(\mu_{2}, v_{2}\right)$ be two IFSs, and the basic operation of them is defined as

$$
\begin{aligned}
I_{1} \oplus I_{2} & =\left(\mu_{1}+\mu_{2}-\mu_{1} \mu_{2}, v_{1} v_{2}\right), \\
I_{1} \otimes I_{2} & =\left(\mu_{1} \mu_{2}, \nu_{1}+v_{2}-v_{1} v_{2}\right), \\
\lambda I_{1} & =\left(1-\left(1-\mu_{1}\right)^{\lambda}, v_{1}^{\lambda}\right), \lambda>0, \\
I_{1}^{\lambda} & =\left(\mu_{1}^{\lambda}, 1-\left(1-v_{1}\right)^{\lambda}\right), \lambda>0 .
\end{aligned}
$$

Definition 3 (see [47]). Let $I_{1}=\left(\mu_{1}, v_{1}\right)$ and $I_{2}=\left(\mu_{2}, v_{2}\right)$ be IFSs, and the defined score and accuracy mathematical functions are

$$
\begin{aligned}
& S\left(I_{1}\right)=\mu_{1}+\mu_{1}\left(1-\mu_{1}-v_{1}\right), S\left(I_{2}\right)=\mu_{2}+\mu_{2}\left(1-\mu_{2}-v_{2}\right), \\
& H\left(I_{1}\right)=\mu_{1}+v_{1}, H\left(I_{2}\right)=\mu_{2}+v_{2} .
\end{aligned}
$$

For two IFSs $I_{1}$ and $I_{2}$ described in Definition 3,

(1) If $s\left(I_{1}\right)<s\left(I_{2}\right)$, then $I_{1}<I_{2}$. 
(2) If $s\left(I_{1}\right)=s\left(I_{2}\right), h\left(I_{1}\right)<h\left(I_{2}\right)$, then $I_{1}<I_{2}$.

(3) If $s\left(I_{1}\right)=s\left(I_{2}\right), h\left(I_{1}\right)=h\left(I_{2}\right)$, then $I_{1}=I_{2}$.

Definition 4 (see [48]). Let $I_{1}=\left(\mu_{1}, v_{1}\right)$ and $I_{2}=\left(\mu_{2}, v_{2}\right)$ be IFSs, and the Euclidean distances and Hamming distances are defined as

$$
\begin{aligned}
& \operatorname{IFE} D\left(I_{1}, I_{2}\right)=\sqrt{\frac{1}{6}\left(\left(\ell_{1}\right)^{2}+\left(\ell_{2}\right)^{2}+\left(\ell_{3}\right)^{2}\right)}, \\
& \text { IFH } D\left(I_{1}, I_{2}\right)=\frac{1}{6}\left(\ell_{1}+\ell_{2}+\ell_{3}\right),
\end{aligned}
$$

where $\quad \ell_{1}=\left|\mu_{1}-\mu_{2}\right|+\left|\nu_{1}-v_{2}\right|+\mid\left(\mu_{1}+1-v_{1}\right)-\left(\mu_{2}+\right.$ $\left.1-v_{2}\right) \mid / 2, \quad \ell_{2}=\pi_{1}+\pi_{2} / 2, \quad$ and $\quad \ell_{3}=\max \left(\left|\mu_{1}-\mu_{2}\right|, \mid \nu_{1}-\right.$ $\left.v_{2}|,| \pi_{1}-\pi_{2} \mid / 2\right)$

\section{CODAS Method for MAGDM with IFSs}

The IF-CODAS method with IFSs is designed. The calculating procedures of the defined method could be described as follows. Let $R=\left\{R_{1}, R_{2}, \ldots R_{n}\right\}$ be the set of attributes and $r=\left\{r_{1}, r_{2}, \ldots r_{n}\right\}$ be weight of attributes $R_{j}$, where $r_{j} \in[0,1], \sum_{j=1}^{n} r_{j}=1$. Let $H=\left\{H_{1}, H_{2}, \ldots H_{l}\right\}$ be a group of DMs that have significant degree of $h=\left\{h_{1}, h_{2}, \ldots h_{l}\right\}$, where $h_{k} \in[0,1], \sum_{k=1}^{l} h_{k}=1$. Let $F=\left\{F_{1}, F_{2}, \ldots F_{m}\right\}$ be a set of alternatives. And $Q=\left(q_{i j}\right)_{m \times n}$ is the overall matrix, $q_{i j}$ with IFSs. Subsequently, the specific calculating procedures are depicted.

Step 1. Set up matrix $Q^{(k)}=\left(q_{i j}^{k}\right)_{m \times n}$ under IFSs and derive the overall matrix $Q=\left(q_{i j}\right)_{m \times n}$ with IFSs.

$$
\begin{aligned}
Q^{(k)}=\left[q_{i j}^{k}\right]_{m \times n}=\left[\begin{array}{cccc}
q_{11}^{k} & q_{12}^{k} & \ldots & q_{1 n}^{k} \\
q_{21}^{k} & q_{22}^{k} & \ldots & q_{2 n}^{k} \\
\vdots & \vdots & \vdots & \vdots \\
q_{m 1}^{k} & q_{m 2}^{k} & \ldots & q_{m n}^{k}
\end{array}\right], \\
Q=\left[q_{i j}\right]_{m \times n}=\left[\begin{array}{cccc}
q_{11} & q_{12} & \ldots & q_{1 n} \\
q_{21} & q_{22} & \ldots & q_{2 n} \\
\vdots & \vdots & \vdots & \vdots \\
q_{m 1} & q_{m 2} & \ldots & q_{m n}
\end{array}\right], \\
q_{i j}=\left(1-\prod_{k=1}^{l}\left(1-\mu_{q_{i j}^{k}}\right)^{h_{k}}, \prod_{k=1}^{l}\left(v_{q_{i j}^{k}}\right)^{h_{k}}\right),
\end{aligned}
$$

where $q_{i j}^{k}$ is the decision value of $F_{i}(i=1,2, \ldots, m)$ for $R_{j}(j=1,2, \ldots, n)$ and the decision maker $H_{k}(k=1,2, \ldots, l)$.

Step 2. Normalize the matrixQ $=\left(q_{i j}\right)_{m \times n}$ to $\widetilde{Q}=\left[\frac{i j}{q}\right]_{m \times n}$.

$$
\tilde{q}_{i j}= \begin{cases}\left(\mu_{i j}, v_{i j}\right), & R_{j} \text { is a benefit attribute } \\ \left(v_{i j}, \mu_{i j}\right), & R_{j} \text { is a cost attribute }\end{cases}
$$

Step 3. Utilize CRITIC model to derive the weight of attributes.

The CRITIC method will be introduced to decide the weights [49]. Then, the calculating steps of such method are presented.

(1) Depending on the normalized matrix $Q^{N}=\left(q_{i j}^{N}\right)_{m \times n}$, the correlation coefficient between attributes is given.

$$
\begin{aligned}
\operatorname{IFCC}_{j t} & =\frac{\sum_{i=1}^{m}\left(H\left(\frac{i j}{q}\right)-H\left(\frac{j}{q}\right)\right)\left(H\left(\frac{i t}{q}\right)-H\left(\frac{t}{q}\right)\right)}{\sqrt{\sum_{i=1}^{m}\left(H\left(\frac{i j}{q}\right)-H\left(\frac{j}{q}\right)\right)^{2}} \sqrt{\sum_{i=1}^{m}\left(H\left(\frac{i t}{q}\right)-H\left(\frac{t}{q}\right)\right)^{2}}}, \quad j, t \\
& =1,2, \ldots, n,
\end{aligned}
$$

where $H\left(\widetilde{q}_{j}\right)=1 / m \sum_{i=1}^{m} H\left(\widetilde{q}_{i j}\right)$ and $H\left(\widetilde{q}_{t}\right)=1 /$ $m \sum_{i=1}^{m} H\left(\tilde{q}_{i t}\right)$.

(2) Calculate attributes' standard deviation.

$$
I F S D_{j}=\sqrt{\frac{1}{m-1} \sum_{i=1}^{m}\left(H\left(\frac{i j}{q}\right)-H\left(\frac{j}{q}\right)\right)^{2}}, j=1,2, \ldots, n,
$$

where $H(\underset{q}{\tilde{q}})=1 / m \sum_{i=1}^{m} H(\underset{q}{\stackrel{i j}{q}})$.

(3) Derive the attributes' weights.

$$
r_{j}=\frac{I F S D_{j} \sum_{t=1}^{n}\left(1-I F C C_{j t}\right)}{\sum_{j=1}^{n}\left(I F S D_{j} \sum_{t=1}^{n}\left(1-I_{F C}\right)\right)},
$$

where $r_{j} \in[0,1]$ and $\sum_{j=1}^{n} r_{j}=1$.

Step 4. Compute weighted matrix with IFSs. The weighted normalized $p_{i j}$ are computed in equations (15) and (16):

$$
\begin{aligned}
P & =\left[p_{i j}\right]_{m \times n}, \\
p_{i j} & =r_{j} \otimes q_{i j}^{N},
\end{aligned}
$$

where $r_{j}$ depicts the weights of $j$ th criterion.

Step 5. Decide intuitionistic fuzzy negative ideal solution (IFNIS) as in equations (13) and (14):

$$
\begin{aligned}
\text { IFNIS } & =\left[\operatorname{IFNIS}_{j}\right]_{1 \times m}, \\
\text { IFNIS }_{j} & =\min _{i} p_{i j},
\end{aligned}
$$

where $\ldots, n\}\}$.

$$
\min _{i} p_{i j}=\left\{r_{k j} \mid S\left(p_{k j}\right)=\min _{i}\left(S\left(p_{k j}\right)\right), k \in\{1,2,\right.
$$

Step 6. Compute intuitionistic fuzzy Euclidean distances and intuitionistic fuzzy Hamming distances from IFNIS as in equations (15) and (16): 


$$
\begin{gathered}
\operatorname{IFED}_{i}=\sum_{j=1}^{n} \operatorname{IFE} D\left(p_{i j} \text { IFNIS }_{j}\right), \\
\text { IFHD }_{i}=\sum_{j=1}^{n} \operatorname{IFH} D\left(p_{i j} \text { IFNIS }_{j}\right) .
\end{gathered}
$$

Step 7. Derive the intuitionistic fuzzy relative assessment (IFRA) matrix as in equations (17) and (18):

$$
\begin{aligned}
& \operatorname{IFRA}=\left[g_{i k}\right]_{m \times m}, \\
& g_{i k}=\left(I F E D_{i}-I_{F E D_{k}}\right)+\left(t\left(I F E D_{i}-I_{F E D_{k}}\right)\right. \\
& \left.\times\left(I F H D_{i}-I F H D_{k}\right)\right) \text {, }
\end{aligned}
$$

where $k \in\{1,2, \ldots, m\}$ and $t$ is defined as the threshold function that is given in the following equation:

$$
t(x)=\left\{\begin{array}{l}
1, \text { if }|x| \geq \theta \\
0, f|x|<\theta
\end{array}\right.
$$

In this research, $\theta=0.02$ is defined for calculations.

Step 8. Obtain the alternative's assessment score $A S_{i}(i=1,2, \cdots, m)$ :

$$
A S_{i}=\sum_{k=1}^{m} g_{i k}
$$

Step 9. Optimal is best.

\section{Numerical Example}

In 2014, Germany became the first country to recognize bitcoin as a currency. At this point, blockchain technology has entered the mainstream society. Many countries pay great attention to developing the blockchain technology and issue various policies or regulations to promote the development of blockchain industry and technology. In October 2016, the Ministry of Industry and Information Technology gave the White Paper on the Development of China's Blockchain Technology and Applications. To some extent, it indicates that the Chinese government also maintains a supportive attitude towards the development of blockchain industry and technology. In December 2016, the State Council issued the National Information Plan for the 13 th Five-Year Plan, which make it as a strategic emerging industry and encourage localities to deploy blockchain industry. In May 2018, a study by the Ministry of Industry and Information Technology showed that the industrial ecology of China's blockchain had initially taken shape. With the prosperity of economy, human beings have been blindly requesting and abusing environmental resources while pursuing their own benefits, which has contributed to increasingly prominent environmental issues. As the major responsible body of environmental pollution, enterprises must play an essential role in protecting environment to achieve sustainable and stable development of economy. In order to effectively alleviate the conflicts between enterprises and environment, it is necessary to establish environmental performance evaluation system. For enterprises, a scientific environmental performance evaluation system can not only prompt themselves to conduct periodical evaluation about environmental behaviors but also help them discover their existing environmental deficiencies and guide them to correct their deficiencies. In such chapter, an empirical application of evaluating CIEP of blockchain industry is provided based on the IF-CODAS method.

Since the government wants to choose one enterprise which has the best environmental behaviors and awareness to reward, there are five potential enterprises $F_{i}(i=1,2,3,4,5)$ preparing to assess their CIEP of blockchain industry. In order to assess these enterprises fairly, five experts $\quad H=\left\{H_{1}, H_{2}, H_{3}, H_{4}, H_{5}\right\}$ (expert's weight $h=(0.20,0.20,0.20,0.20,0.20))$ are invited to depict their decision information. All experts express their decision information through four attributes: (1) $R_{1}$ is environmental training and awareness; (2) $R_{2}$ is waste disposal cost; (3) $R_{3}$ is the ability to implement environment concerned design; and (4) $R_{4}$ is environmental protection equipment investment. Evidently, $R_{2}$ is cost attribute, while $R_{1}, R_{3}$, and $R_{4}$ are benefit attributes. To make this assessment, the DMs convey their assessments by using the linguistic variables. The linguistic variables for ratings of alternatives are recorded in Table 1.

Step 1. Set up each DM's matrix $Q^{(k)}=\left(q_{i j}^{k}\right)_{m \times n}(i=$ $1,2, \ldots, m, j=1,2, \ldots, n)$ with IFSs as in Tables $2-6$ by utilizing linguistic terms from Table 1. From these five tables and equations (5)-(7), the overall matrix can be obtained. The results are listed in Table 7.

Step 2. Normalize the matrix $Q=\left[\begin{array}{c}i j \\ q\end{array}\right]_{m \times n}$ to $Q^{N}=\left[q_{i j}^{N}\right]_{m \times n}($ see Table 8$)$.

Step 3. Obtain the attribute weight $r_{j}(j=1,2, \ldots, n)$ by using the CRITIC method (Table 9).

Step 4. Obtain intuitionistic fuzzy weighted normalized assessing matrix (Table 10).

Step 5. Decide IFNIS by utilizing equations (13) and (14) in terms of Table 10, and the calculating results are given in Table 11.

Step 6. Derive the alternatives' $E D$ and $H D$ by utilizing equations (15) and (16). The results are recorded in Table 12.

Step 7. Obtain the $R A$ matrix by utilizing equations (17)-(19) as in Table 13.

Step 8. Calculate each alternative's total assessment score $(A S)$ as given in equation (20), and the corresponding results are recorded in Table 14 .

Step 9. Relying on the calculating values of AS, the order of these five alternatives is $F_{2}>F_{4}>F_{3}>F_{1}>F_{5}$, and $F_{2}$ is the optimal enterprise. 
TABLE 1: Linguistic terms for ratings of these alternatives.

\begin{tabular}{lc}
\hline Linguistic term & IFSs \\
\hline Certainly low (CL) & $(0.1,0.9)$ \\
Very low (VL) & $(0.2,0.8)$ \\
Low (L) & $(0.3,0.7)$ \\
Below medium (BM) & $(0.4,0.6)$ \\
Exactly equal (EE) & $(0.5,0.5)$ \\
Above medium (AM) & $(0.6,0.4)$ \\
High (H) & $(0.7,0.3)$ \\
Very high (VH) & $(0.8,0.2)$ \\
Certainly high (CH) & $(0.9,0.1)$ \\
\hline
\end{tabular}

TABLE 2: Intuitionistic fuzzy matrix by $H_{1}$.

\begin{tabular}{lcccc}
\hline & $R_{1}$ & $R_{2}$ & $R_{3}$ & $R_{4}$ \\
\hline$F_{1}$ & $\mathrm{~L}$ & $\mathrm{BM}$ & $\mathrm{VL}$ & $\mathrm{BM}$ \\
$F_{2}$ & $\mathrm{EE}$ & $\mathrm{CL}$ & $\mathrm{H}$ & $\mathrm{VH}$ \\
$F_{3}$ & $\mathrm{BM}$ & $\mathrm{L}$ & $\mathrm{EE}$ & $\mathrm{VL}$ \\
$F_{4}$ & $\mathrm{~L}$ & $\mathrm{VL}$ & $\mathrm{BM}$ & $\mathrm{BM}$ \\
$F_{5}$ & $\mathrm{VL}$ & $\mathrm{BM}$ & $\mathrm{AM}$ & $\mathrm{AM}$ \\
\hline
\end{tabular}

TABLe 3: Intuitionistic fuzzy matrix by $\mathrm{H}_{2}$.

\begin{tabular}{lcccc}
\hline & $R_{1}$ & $R_{2}$ & $R_{3}$ & $R_{4}$ \\
\hline$F_{1}$ & $\mathrm{~L}$ & $\mathrm{BM}$ & $\mathrm{H}$ & $\mathrm{EE}$ \\
$F_{2}$ & $\mathrm{H}$ & $\mathrm{L}$ & $\mathrm{EE}$ & $\mathrm{AM}$ \\
$F_{3}$ & $\mathrm{EE}$ & $\mathrm{VL}$ & $\mathrm{EE}$ & $\mathrm{H}$ \\
$F_{4}$ & $\mathrm{BM}$ & $\mathrm{EE}$ & $\mathrm{AM}$ & $\mathrm{VH}$ \\
$F_{5}$ & $\mathrm{AM}$ & $\mathrm{BM}$ & $\mathrm{BM}$ & $\mathrm{EE}$ \\
\hline
\end{tabular}

TABLe 4: Intuitionistic fuzzy matrix by $\mathrm{H}_{3}$.

\begin{tabular}{lcccc}
\hline & $R_{1}$ & $R_{2}$ & $R_{3}$ & $R_{4}$ \\
\hline$F_{1}$ & $\mathrm{EE}$ & $\mathrm{AM}$ & $\mathrm{L}$ & $\mathrm{BM}$ \\
$F_{2}$ & $\mathrm{AM}$ & $\mathrm{BM}$ & $\mathrm{BM}$ & $\mathrm{H}$ \\
$F_{3}$ & $\mathrm{~L}$ & $\mathrm{BM}$ & $\mathrm{VL}$ & $\mathrm{AM}$ \\
$F_{4}$ & $\mathrm{AM}$ & $\mathrm{L}$ & $\mathrm{AM}$ & $\mathrm{L}$ \\
$F_{5}$ & $\mathrm{BM}$ & $\mathrm{AM}$ & $\mathrm{L}$ & $\mathrm{AM}$ \\
\hline
\end{tabular}

TABLE 5: Intuitionistic fuzzy matrix by $H_{4}$.

\begin{tabular}{lcccc}
\hline & $R_{1}$ & $R_{2}$ & $R_{3}$ & $R_{4}$ \\
\hline$F_{1}$ & $\mathrm{AM}$ & $\mathrm{L}$ & $\mathrm{H}$ & $\mathrm{VL}$ \\
$F_{2}$ & $\mathrm{CH}$ & $\mathrm{VL}$ & $\mathrm{CH}$ & $\mathrm{BM}$ \\
$F_{3}$ & $\mathrm{BM}$ & $\mathrm{BM}$ & $\mathrm{AM}$ & $\mathrm{AM}$ \\
$F_{4}$ & $\mathrm{H}$ & $\mathrm{L}$ & $\mathrm{AM}$ & $\mathrm{CL}$ \\
$F_{5}$ & $\mathrm{~L}$ & $\mathrm{BM}$ & $\mathrm{EE}$ & $\mathrm{L}$ \\
\hline
\end{tabular}

TABLE 7: Overall intuitionistic fuzzy matrix.

\begin{tabular}{lcccc}
\hline & $R_{1}$ & $R_{2}$ & $R_{3}$ & $R_{4}$ \\
\hline \multirow{2}{*}{$F_{1}$} & $(0.5061$, & $(0.4294$, & $(0.4877$, & $(0.4092$, \\
& $0.4939)$ & $0.5706)$ & $0.5123)$ & $0.5908)$ \\
$F_{2}$ & $(0.7395$, & $(0.2669$, & $(0.6755$, & $(0.6435$, \\
& $0.2605)$ & $0.7331)$ & $0.3245)$ & $0.3565)$ \\
\multirow{2}{*}{$F_{3}$} & $(0.4034$, & $(0.3057$, & $(0.4622$, & $(0.5148$, \\
& $0.5966)$ & $0.6943)$ & $0.5378)$ & $0.4852)$ \\
$F_{4}$ & $(0.4877$, & $(0.3716$, & $(0.5905$, & $(0.4294$, \\
& $0.5123)$ & $0.6284)$ & $0.4095)$ & $0.5706)$ \\
$F_{5}$ & $(0.3446$, & $(0.4467$, & $(0.4695$, & $(0.4768$, \\
& $0.6554)$ & $0.5533)$ & $0.5305)$ & $0.5232)$ \\
\hline
\end{tabular}

TABLE 8: The normalized intuitionistic fuzzy matrix.

\begin{tabular}{lcccc}
\hline & $R_{1}$ & $R_{2}$ & $R_{3}$ & $R_{4}$ \\
\hline \multirow{2}{*}{$F_{1}$} & $(0.5061$, & $(0.5706$, & $(0.4877$, & $(0.4092$, \\
& $0.4939)$ & $0.4294)$ & $0.5123)$ & $0.5908)$ \\
$F_{2}$ & $(0.7395$, & $(0.7331$, & $(0.6755$, & $(0.6435$, \\
& $0.2605)$ & $0.2669)$ & $0.3245)$ & $0.3565)$ \\
$F_{3}$ & $(0.4034$, & $(0.6943$, & $(0.4622$, & $(0.5148$, \\
& $0.5966)$ & $0.3057)$ & $0.5378)$ & $0.4852)$ \\
$F_{4}$ & $(0.4877$, & $(0.6284$, & $(0.5905$, & $(0.4294$, \\
& $0.5123)$ & $0.3716)$ & $0.4095)$ & $0.5706)$ \\
$F_{5}$ & $(0.3446$, & $(0.5533$, & $(0.4695$, & $(0.4768$, \\
& $0.6554)$ & $0.4467)$ & $0.5305)$ & $0.5232)$ \\
\hline
\end{tabular}

TABLe 9: The attribute weights $r_{j}$.

\begin{tabular}{ccccc}
\hline & $R_{1}$ & $R_{2}$ & $R_{3}$ & $R_{4}$ \\
\hline$r_{j}$ & 0.3347 & 0.2002 & 0.2286 & 0.2365 \\
\hline
\end{tabular}

TABLE 10: Intuitionistic fuzzy weighted normalized performance values of alternatives.

\begin{tabular}{lcccc}
\hline & $R_{1}$ & $R_{2}$ & $R_{3}$ & $R_{4}$ \\
\hline \multirow{2}{*}{$F_{1}$} & $(0.2103$, & $(0.1557$, & $(0.1418$, & $(0.1170$, \\
& $0.7897)$ & $0.8443)$ & $0.8582)$ & $0.8830)$ \\
$F_{2}$ & $(0.3625$, & $(0.2324$, & $(0.2268$, & $(0.2165$, \\
& $0.6375)$ & $0.7676)$ & $0.7732)$ & $0.7835)$ \\
$F_{3}$ & $(0.1587$, & $(0.2112$, & $(0.1322$, & $(0.1572$, \\
& $0.8413)$ & $0.7888)$ & $0.8678)$ & $0.8428)$ \\
$F_{4}$ & $(0.2006$, & $(0.1798$, & $(0.1846$, & $(0.1243$, \\
& $0.7994)$ & $0.8202)$ & $0.8154)$ & $0.8757)$ \\
$F_{5}$ & $(0.1318$, & $(0.1490$, & $(0.1349$, & $(0.1421$, \\
& $0.8682)$ & $0.8510)$ & $0.8651)$ & $0.8579)$ \\
\hline
\end{tabular}

TABLE 6: Intuitionistic fuzzy matrix by $H_{5}$.

\begin{tabular}{lcccc}
\hline & $R_{1}$ & $R_{2}$ & $R_{3}$ & $R_{4}$ \\
\hline$F_{1}$ & $\mathrm{H}$ & $\mathrm{BM}$ & $\mathrm{L}$ & $\mathrm{EE}$ \\
$F_{2}$ & $\mathrm{VH}$ & $\mathrm{L}$ & $\mathrm{AM}$ & $\mathrm{AM}$ \\
$F_{3}$ & $\mathrm{BM}$ & $\mathrm{VL}$ & $\mathrm{EE}$ & $\mathrm{L}$ \\
$F_{4}$ & $\mathrm{~L}$ & $\mathrm{EE}$ & $\mathrm{H}$ & $\mathrm{VL}$ \\
$F_{5}$ & $\mathrm{CL}$ & $\mathrm{BM}$ & $\mathrm{EE}$ & $\mathrm{L}$ \\
\hline
\end{tabular}

TABLE 11: IFNIS.

\begin{tabular}{lc}
\hline & IFNIS \\
\hline$R_{1}$ & $(0.1318,0.8682)$ \\
$R_{2}$ & $(0.1490,0.8510)$ \\
$R_{3}$ & $(0.1322,0.8678)$ \\
$R_{4}$ & $(0.1170,0.8830)$ \\
\hline
\end{tabular}


TABLE 12: Alternatives' Euclidean and Hamming distances.

\begin{tabular}{lcc}
\hline & ED & HD \\
\hline$F_{1}$ & 0.0474 & 0.0865 \\
$F_{2}$ & 0.2540 & 0.4638 \\
$F_{3}$ & 0.0647 & 0.1180 \\
$F_{4}$ & 0.0796 & 0.1453 \\
$F_{5}$ & 0.0139 & 0.0253 \\
\hline
\end{tabular}

TABLE 13: Relative assessment matrix.

\begin{tabular}{cccccc}
\hline & $\mathrm{F}_{1}$ & $\mathrm{~F}_{2}$ & $\mathrm{~F}_{3}$ & $\mathrm{~F}_{4}$ & $\mathrm{~F}_{5}$ \\
\hline$F_{1}$ & 0.0000 & -0.5840 & -0.0173 & -0.0911 & 0.0946 \\
$F_{2}$ & 0.5840 & 0.0000 & 0.5351 & 0.4929 & 0.6786 \\
$F_{3}$ & 0.0173 & -0.5351 & 0.0000 & -0.0149 & 0.1435 \\
$F_{4}$ & 0.0911 & -0.4929 & 0.0149 & 0.0000 & 0.1857 \\
$F_{5}$ & -0.0946 & -0.6786 & -0.1435 & -0.1857 & 0.0000 \\
\hline
\end{tabular}

TABLe 14: Assessment score.

\begin{tabular}{lc}
\hline Alternative & Assessment score \\
\hline$F_{1}$ & -0.5977 \\
$F_{2}$ & 2.2906 \\
$F_{3}$ & -0.3893 \\
$F_{4}$ & -0.2012 \\
$F_{5}$ & -1.1024 \\
\hline
\end{tabular}

\section{Conclusion}

The CIEP of blockchain industry is of great significance in the process of enterprise production, management, and competition. Thus, it is urgent for enterprises to choose an effective CIEP evaluation system. This paper defined an effective solution idea for this kind of issue, since it builds the novel intuitive distance-based IF-CODAS method for evaluation system of CIEP. Then, a corresponding numerical example is used to confirm that the IF-CODAS method is reasonable. The main contribution of this paper is that this paper solves the multiattribute group decision making (MAGDM) problem, uses the novel Euclidean distances and Hamming distances, and utilizes the CRITIC model to derive the weight of attributes. Future research could tackle the interdependency of attributes by utilizing some other methods including ANP, AHP, and information entropy. Furthermore, the developed method could be used to tackle some other MAGDM like project selection [50-54] and site selection [55-57]. It could also be applied to some other diverse uncertain and ambiguous settings [58-66].

\section{Data Availability}

The data used to support the findings of this study are included within the article.

\section{Conflicts of Interest}

The author declares that there are no conflicts of interest regarding the publication of this article.

\section{Acknowledgments}

This study was supported by the Science and Technology Development Plan Projects of Jilin Province (no. 20170101081JC).

\section{References}

[1] S. Karagoz, M. Deveci, V. Simic, N. Aydin, and U. Bolukbas, "A novel intuitionistic fuzzy MCDM-based CODAS approach for locating an authorized dismantling center: a case study of Istanbul," Waste Management \& Research, vol. 38, no. 6, pp. 660-672, 2020.

[2] P. Rao, O. la O' Castillo, P. S. Intal, and A. Sajid, "Environmental indicators for small and medium enterprises in the Philippines: an empirical research," Journal of Cleaner Production, vol. 14, no. 5, pp. 505-515, 2006.

[3] S. Xie and K. Hayase, "Corporate environmental performance evaluation: a measurement model and a new concept," Business Strategy and the Environment, vol. 16, no. 2, pp. 148-168, 2007.

[4] C. Trumpp, J. Endrikat, C. Zopf, and E. Guenther, "Definition, conceptualization, and measurement of corporate environmental performance: a critical examination of a multidimensional construct," Journal of Business Ethics, vol. 126, no. 2, pp. 185-204, 2015.

[5] M. Puig, C. Wooldridge, and R. M. Darbra, "Identification and selection of Environmental Performance Indicators for sustainable port development," Marine Pollution Bulletin, vol. 81, no. 1, pp. 124-130, 2014.

[6] F. Cucchiella, I. D’Adamo, M. Gastaldi, S. L. Koh, and P. Rosa, "A comparison of environmental and energetic performance of European countries: a sustainability index," Renewable and Sustainable Energy Reviews, vol. 78, pp. 401-413, 2017.

[7] E.-O. Elena, J. M.-T. María, Á.F.-I. María, and M. R.-L. Juana, "Measuring corporate environmental performance: a methodology for sustainable development," Business Strategy and the Environment, vol. 26, pp. 142-162, 2015.

[8] Z. Jiang, H. Zhang, W. Yan, M. Zhou, and G. Li, "A method for evaluating environmental performance of machining systems," International Journal of Computer Integrated Manufacturing, vol. 25, no. 6, pp. 488-495, 2012.

[9] Z. Jiang, H. Zhang, and J. W. Sutherland, "Development of an environmental performance assessment method for manufacturing process plans," International Journal of Advanced Manufacturing Technology, vol. 58, no. 5-8, pp. 783790, 2012.

[10] D. F. Li and C. T. Cheng, "New similarity measures of intuitionistic fuzzy sets and application to pattern recognitions," Pattern Recognition Letters, vol. 23, pp. 221-225, 2002.

[11] T. He, G. Wei, J. Wu, and C. Wei, "QUALIFLEX method for evaluating human factors in construction project management with Pythagorean 2-tuple linguistic information," Journal of Intelligent and Fuzzy Systems, vol. 40, no. 3, pp. 4039-4050, 2021.

[12] S. J. Shi-Jay Chen and S. M. Shyi-Ming Chen, "Fuzzy risk analysis based on similarity measures of generalized fuzzy numbers," IEEE Transactions on Fuzzy Systems, vol. 11, no. 1, pp. 45-56, 2003.

[13] J. Li, L. Wen, G. Wei, J. Wu, and C. Wei, "New similarity and distance measures of Pythagorean fuzzy sets and its application to selection of advertising platforms," Journal of Intelligent and Fuzzy Systems, vol. 40, no. 3, pp. 5403-5419, 2021. 
[14] M. Zhao, G. Wei, C. Wei, and J. Wu, "Pythagorean fuzzy TODIM method based on the cumulative prospect theory for MAGDM and its application on risk assessment of science and technology projects," International Journal of Fuzzy Systems, vol. 23, no. 4, pp. 1027-1041, 2021.

[15] L. A. Zadeh, "Fuzzy sets," Information and Control, vol. 8, no. 3, pp. 338-353, 1965.

[16] K. T. Atanassov, "Intuitionistic fuzzy sets," Fuzzy Sets and Systems, vol. 20, no. 1, pp. 87-96, 1986.

[17] J.-C. Liu and D.-F. Li, "Corrections to "TOPSIS-Based nonlinear-programming methodology for multi-attribute decision making with interval-valued intuitionistic fuzzy sets" [apr 10 299-311]," IEEE Transactions on Fuzzy Systems, vol. 26, no. 1, p. 391, 2018.

[18] G.-F. Yu, D.-F. Li, and W. Fei, "A novel method for heterogeneous multi-attribute group decision making with preference deviation," Computers \& Industrial Engineering, vol. 124, pp. 58-64, 2018.

[19] G.-F. Yu, D.-F. Li, J.-M. Qiu, and X.-X. Zheng, "Some operators of intuitionistic uncertain 2-tuple linguistic variables and application to multi-attribute group decision making with heterogeneous relationship among attributes," Journal of Intelligent and Fuzzy Systems, vol. 34, no. 1, pp. 599-611, 2018.

[20] L. Xiao, S. Zhang, G. Wei et al., "Green supplier selection in steel industry with intuitionistic fuzzy Taxonomy method," Journal of Intelligent and Fuzzy Systems, vol. 39, no. 5, pp. 7247-7258, 2020.

[21] M. Zhao, G. Wei, C. Wei, J. Wu, and Y. Wei, "Extended CPTTODIM method for interval-valued intuitionistic fuzzy MAGDM and its application to urban ecological risk assessment," Journal of Intelligent and Fuzzy Systems, vol. 40, no. 3, pp. 4091-4106, 2021.

[22] Z. Zeshui Xu and R. R. Yager, "Intuitionistic fuzzy bonferroni means," IEEE Transactions on Systems, Man, and Cybernetics, Part B (Cybernetics), vol. 41, no. 2, pp. 568-578, 2011.

[23] Z. Xu and Q. Chen, "A multi-criteria decision making procedure based on interval-valued intuitionistic fuzzy bonferroni means," Journal of Systems Science and Systems Engineering, vol. 20, no. 2, pp. 217-228, 2011.

[24] W.-L. Hung and M.-S. Yang, "Similarity measures of intuitionistic fuzzy sets based on Lp metric," International Journal of Approximate Reasoning, vol. 46, no. 1, pp. 120-136, 2007.

[25] J. H. Park, K. M. Lim, J. S. Park, and Y. C. Kwun, "Distances between interval-valued intuitionistic fuzzy sets," in Proceedings of the 2007 International Symposium on Nonlinear Dynamics, Shanghai China, October 2007.

[26] C. C. Hung, L. H. Chen, and S. I. Ao, "A fuzzy TOPSIS decision making model with entropy weight under intuitionistic fuzzy environment," 2009, http://citeseerx.ist.psu. edu/viewdoc/summary?doi=10.1.1.148.9140.

[27] G. Beliakov, S. James, J. Mordelová, T. Rückschlossová, and R. R. Yager, "Generalized Bonferroni mean operators in multi-criteria aggregation," Fuzzy Sets and Systems, vol. 161, no. 17, pp. 2227-2242, 2010.

[28] J. Ye, "Fuzzy cross entropy of interval-valued intuitionistic fuzzy sets and its optimal decision-making method based on the weights of alternatives," Expert Systems with Applications, vol. 38, no. 5, pp. 6179-6183, 2011.

[29] M. Xia, Z. Xu, and B. Zhu, "Generalized intuitionistic fuzzy Bonferroni means," International Journal of Intelligent Systems, vol. 27, no. 1, pp. 23-47, 2012.

[30] Y. He, Z. He, G. Wang, and H. Chen, "Hesitant fuzzy power bonferroni means and their application to multiple attribute decision making," IEEE Transactions on Fuzzy Systems, vol. 23, no. 5, pp. 1655-1668, 2015.

[31] M. I. Ali, F. Feng, T. Mahmood, I. Mahmood, and H. Faizan, "A graphical method for ranking Atanassov's intuitionistic fuzzy values using the uncertainty index and entropy," International Journal of Intelligent Systems, vol. 34, no. 10, pp. 2692-2712, 2019.

[32] F. Xiao, "A distance measure for intuitionistic fuzzy sets and its application to pattern classification problems," IEEE Transactions on Systems, Man, and Cybernetics: Systems, vol. 51, no. 6, pp. 3980-3992, 2021.

[33] L. Xiao, G. Wei, Y. Guo, and X. Chen, "Taxonomy method for multiple attribute group decision making based on intervalvalued intuitionistic fuzzy with entropy," Journal of Intelligent and Fuzzy Systems, pp. 1-15, 2021.

[34] S. Zhang, H. Gao, G. Wei, and X. Chen, "Grey relational analysis method based on cumulative prospect theory for intuitionistic fuzzy multi-attribute group decision making," Journal of Intelligent and Fuzzy Systems, vol. 41, no. 2, pp. 3783-3795, 2021.

[35] M. Zhao, G. Wei, X. Chen, and Y. Wei, "Intuitionistic fuzzy MABAC method based on cumulative prospect theory for multiple attribute group decision making," International Journal of Intelligent Systems, vol. 36, no. 11, pp. 6337-6359, 2021.

[36] F. Y. Xiao, "EFMCDM: evidential fuzzy multicriteria decision making based on belief entropy," IEEE Transactions on Fuzzy Systems, vol. 28, pp. 1477-1491, 2020.

[37] M. Zhao, G. Wei, C. Wei, and J. Wu, "Improved TODIM method for intuitionistic fuzzy MAGDM based on cumulative prospect theory and its application on stock investment selection," International Journal of Machine Learning and Cybernetics, vol. 12, no. 3, pp. 891-901, 2021.

[38] M. K. Ghorabaee, E. K. Zavadskas, Z. Turskis, and J. Antucheviciene, "A new combinative distance-based assessment (CODAS) method for multi-criteria decisionmaking," Econ papers, vol. 50, pp. 25-44, 2017.

[39] M. Keshavarz Ghorabaee, M. Amiri, E. K. Zavadskas, R. Hooshmand, and J. Antuchevičienè, "Fuzzy extension of the CODAS method for multi-criteria market segment evaluation," Journal of Business Economics and Management, vol. 18, no. 1, pp. 1-19, 2017.

[40] D. Pamučar, I. Badi, K. Sanja, and R. Obradović, "A novel approach for the selection of power-generation technology using a linguistic neutrosophic CODAS method: a case study in Libya," Energies, vol. 11, no. 9, p. 2489, 2018.

[41] J. Roy, S. Das, S. Kar, and D. Pamučar, "An extension of the CODAS approach using interval-valued intuitionistic fuzzy set for sustainable material selection in construction projects with incomplete weight information," Symmetry, vol. 11, no. 3, p. 393, 2019.

[42] J. Lan, J. Wu, Y. Guo, C. Wei, G. Wei, and H. Gao, "CODAS methods for multiple attribute group decision making with interval-valued bipolar uncertain linguistic information and their application to risk assessment of Chinese enterprises' overseas mergers and acquisitions," Economic ResearchEkonomska Istraživanja, pp. 1-17, 2021.

[43] T. He, S. Zhang, G. Wei, R. Wang, J. Wu, and C. Wei, "CODAS method for 2-tuple linguistic pythagorean fuzzy multiple attribute group decision making and its application to financial management performance assessment," Technological and Economic Development of Economy, vol. 26, no. 4, pp. 920-932, 2020. 
[44] F. Lei, G. Wei, and X. Chen, "Model-based evaluation for online shopping platform with probabilistic double hierarchy linguistic CODAS method," International Journal of Intelligent Systems, vol. 36, no. 9, pp. 5339-5358, 2021.

[45] C. Wei, J. Wu, Y. Guo, and G. Wei, "Green supplier selection based on CODAS method in probabilistic uncertain linguistic environment," Technological and Economic Development of Economy, vol. 27, no. 3, pp. 530-549, 2021.

[46] Z. Xu and R. R. Yager, "Some geometric aggregation operators based on intuitionistic fuzzy sets," International Journal of General Systems, vol. 35, no. 4, pp. 417-433, 2006.

[47] H.-W. Liu and G.-J. Wang, "Multi-criteria decision-making methods based on intuitionistic fuzzy sets," European Journal of Operational Research, vol. 179, no. 1, pp. 220-233, 2007.

[48] X. Luo and X. Wang, "Extended VIKOR method for intuitionistic fuzzy multiattribute decision-making based on a new distance measure," Mathematical Problems in Engineering, vol. 2017, pp. 1-16, Article ID 4072486, 2017.

[49] D. Diakoulaki, G. Mavrotas, and L. Papayannakis, "Determining objective weights in multiple criteria problems: the critic method," Computers \& Operations Research, vol. 22, no. 7, pp. 763-770, 1995.

[50] J. P. Tian, Z. Huo, F. J. Ma, X. Gao, and Y. B. Wu, “Application and selection of remediation technology for OCPs-contaminated sites by decision-making methods," International Journal of Environmental Research and Public Health, vol. 16, 2019.

[51] Y. Wu, J. Wang, S. Ji, Z. Song, and Y. Ke, "Optimal investment selection of industrial and commercial rooftop distributed PV project based on combination weights and cloud-TODIM model from SMEs' perspectives," Journal of Cleaner Production, vol. 234, pp. 534-548, 2019.

[52] J. Lu, S. Zhang, J. Wu, and Y. Wei, "COPRAS method for multiple attribute group decision making under picture fuzzy environment and their application to green supplier selection," Technological and Economic Development of Economy, vol. 27, no. 2, pp. 369-385, 2021.

[53] M. Zhao, G. Wei, C. Wei, and Y. Guo, "CPT-TODIM method for bipolar fuzzy multi-attribute group decision making and its application to network security service provider selection," International Journal of Intelligent Systems, vol. 36, no. 5, pp. 1943-1969, 2021.

[54] M. Zhao, G. Wei, Y. Guo, and X. Chen, "CPT-TODIM method for interval-valued bipolar fuzzy multiple attribute group decision making and application to industrial control security service provider selection," Technological and Economic Development of Economy, vol. 27, no. 5, pp. 1186-1206, 2021.

[55] C. N. Wang, M. H. Hsueh, and D. F. Lin, "Hydrogen power plant site selection under fuzzy multicriteria decision-making (FMCDM) environment conditions," Symmetry-Basel, vol. 11, 2019.

[56] J. Guo, J. L. Yin, L. Zhang, Z. F. Lin, and X. Li, "Extended TODIM method for CCUS storage site selection under probabilistic hesitant fuzzy environment," Applied Soft Computing, vol. 93, Article ID 106381, 2020.

[57] M. W. Lin, C. Huang, and Z. S. Xu, "MULTIMOORA based MCDM model for site selection of car sharing station under picture fuzzy environment," Sustainable Cities and Society, vol. 53, Article ID 101873, 2020.

[58] E. K. Zavadskas, A. Kaklauskas, and T. Vilutienè, "Multicriteria evaluation of apartment blocks maintenance contractors: Lithuanian case study," International Journal of
Strategic Property Management, vol. 13, no. 4, pp. 319-338, 2009.

[59] P. Liu, T. Mahmood, and Q. Khan, "Multi-attribute decisionmaking based on prioritized aggregation operator under hesitant intuitionistic fuzzy linguistic environment," Symmetry, vol. 9, no. 11, p. 270, 2017.

[60] A. Hussain, M. I. Ali, and T. Mahmood, "Pythagorean fuzzy soft rough sets and their applications in decision-making," Journal of Taibah University for Science, vol. 14, no. 1, pp. 101-113, 2020.

[61] G. Wei, C. Wei, J. Wu, and Y. Guo, "Probabilistic linguistic multiple attribute group decision making for location planning of electric vehicle charging stations based on the generalized Dice similarity measures," Artificial Intelligence Review, vol. 54, no. 6, pp. 4137-4167, 2021.

[62] Y. He, G. Wei, X. Chen, and Y. Wei, "Bidirectional projection method for multi-attribute group decision making under probabilistic uncertain linguistic environment," Journal of Intelligent and Fuzzy Systems, vol. 41, no. 1, pp. 1429-1443, 2021.

[63] R. Chinram, A. Hussain, T. Mahmood, and M. I. Ali, "EDAS method for multi-criteria group decision making based on intuitionistic fuzzy rough aggregation operators," IEEE Access, vol. 9, pp. 10199-10216, 2021.

[64] Y. Huang, R. Lin, and X. Chen, "An enhancement EDAS method based on prospect theory," Technological and Economic Development of Economy, vol. 27, no. 5, pp. 1019-1038, 2021.

[65] S.-P. Wan and D.-F. Li, "Fuzzy LINMAP approach to heterogeneous MADM considering comparisons of alternatives with hesitation degrees," Omega, vol. 41, no. 6, pp. 925-940, 2013.

[66] S.-P. Wan, D.-F. Li, and Z.-F. Rui, "Possibility mean, variance and covariance of triangular intuitionistic fuzzy numbers," Journal of Intelligent and Fuzzy Systems, vol. 24, no. 4, pp. 847-858, 2013. 